FERMILAB-Conf-96/289

\title{
Cryogenic Testing and Analysis Associated with Tevatron Lower Temperature Operation
}

\author{
J.C. Theilacker \\ Fermi National Accelerator Laboratory \\ P.O. Box 500, Batavia, Illinois 60510
}

September 1996

Presented at the Cryogenic Engineering Conference and International Cryogenic Materials Conference (CEC/1CMC 95), Columbus, Ohio, July 17-21, 1995. 


\section{Disclaimer}

This report was prepared as an account of work sponsored by an agency of the United States Government. Neither the United States Government nor any agency thereof, nor any of their employees, makes any warranty, express or implied, or assumes any legal liability or responsibility for the accuracy, completeness or usefulness of any information, apparatus, product or process disclosed, or represents that its use would not infringe privately owned rights. Reference herein to any specific commercial product, process or service by trade name, trademark, manufacturer or otherwise, does not necessarily constitute or imply its endorsement, recommendation or favoring by the United States Government or any agency thereof. The views and opinions of authors expressed herein do not necessarily state or reflect those of the United States Government or any agency thereof.

\section{Distribution}

Approved for public release: further dissemination unlimited. 


\title{
CRYOGENIC TESTING AND ANALYSIS ASSOCIATED WITH TEVATRON LOWER TEMPERATURE OPERATION
}

\author{
J. C. Theilacker \\ Fermi National Accelerator Laboratory* \\ Batavia, IL, 60510, USA
}

\begin{abstract}
An upgrade of the Tevatron cryogenic system was installed and commissioned in 1993 to allow lower temperature operation. ${ }^{1}$ As a result, higher energy operation of the Fermilat superconducting Tevatron accelerator is possible. Following the installation and initial commissioning, it was decided to continue the current colliding heam physics run at the previous energy of $900 \mathrm{GeV}$. This has allowed us to perform parasitic lower temperature tests in the Tevatron over the last year and a half.

This paper presents the results of operational experiences and thermal and hydraulic testing which have taken place. The primary goal of the testing is to better understand the operation of the cold compressor system, associated instrumentation, and the performance of the existing magnet system during lower temperature operation. This will lead to a tentatively scheduled higher energy test run in the fall of 1995 .

The test results have shown that more elaborate controlling methods are necessary in order to achieve reliable system operation. Fortunately, our new satellite refrigerator controls system is capable of the expansion necessary to reach our goal. ${ }^{2}$ New features are being added to the controls systems which will allow for more intelligent control and hetter diagnostics for component monitoring and trending.
\end{abstract}

\section{INTRODUCTION}

It is desirable to increase the energy of the superconducting Tevatton accelerator firom its current level of $900 \mathrm{GeV}$ to $1000 \mathrm{GeV}$. The current carrying capability of the superconductor used in the Tevatron improves by $15 \%$ per degree Kelvin in the range of interest. A cryogenic system upgrade was installed in 1993 which has the capability of reducing the magnet temperature by as much as $1 \mathrm{~K}$. Centrifugal cold helium vapor compressors were installed in each of the twenty-four saltellite relrigctators to accomplish this."

Each of the satellite relrigerators cools two $125 \mathrm{~m}$ long magnet strings. The superconducting coils are bathed in subcooled liquid at $0.22 \mathrm{MPa}$. In each magnet, half of the single-phase $(1 \varnothing)$ stream bathes the superconducting coils and half is cooled by an annular two-phase $(2 \varnothing)$ helium passage. The two lo streams mix at the end of each magnet. Static (heat leak) and dynamic (AC loss) heal loads are removed by the latent heat of the

\footnotetext{
* Work supported by the U.S. Departinemt of Energy under contract No. DE- $\triangle(02-76 C H(0) 30(X)$.
} 
liquid in the 20 passage. The remaining $2 \varnothing$ helium from both magnet strings retums to a subcooling dewar at the refrigerator.

Figure 1 shows a schematic layout of a satellite refrigerator with one of it's two magnet strings. Components new to the lower temperature upgrade include the cold compressor, 130 liter subcooling dewar and provisions for a void fraction sensor on the 20 retum from the magnet strings.

The subcooling dewar serves two purposes. First, it separates the liquid and vapor in order to ensure that the centrifugal cold compressor only pumps on saturated vapor. Second, it provides a thermal huffer between the refrigerator and the magnet strings. The returning liquid is vaporized by a heat exchanger which subcools the outgoing stream of the refrigerator. The level of liquid in the subcooling dewar is maintained by adjusting the amount of liquid helium drawn from the Central Helium Liquefier (CHL).

Tests were performed on the cold compressors and the behavior of the magnet strings during the current $900 \mathrm{GeV}$ Collider Run $1 \mathrm{~B}$. Considerable testing was performed parasitic to collider operations. However, all of the tests presented in this paper required dedicated use of the Tevatron. In most cases, this time was made available while another system was down, making physics or beam related studies in the Tevatron impossible.

Figure 1 also shows the instrumentation available for characterizing the behavior of the Tevatron magnet systems during our tests. Thermometry used is shown as a "T" and is generally a carbon resistor thermometer. The redundant thermometer shown on the lø inlet and outlet is a vapor pressure thermometer as is the thermometer on the cold compressor inlet. Pressure measurements are made by standard capacitance type transducers and are shown as a "P" or "DP" for differential. Flow is measured with a liquid helium venturi and utilizes a warm differential pressure transducer, shown as " $F$ " in Figure 1.

The layout and instrumentation available for a typical $125 \mathrm{~m}$ long magnet string is also shown in Figure 1. Temperature of the 16 is measured every half cell. A half cell consist. of four dipole magnets ("D" in Figure 1), a quadrupole magnet $(Q)$, and a spool piece (S).

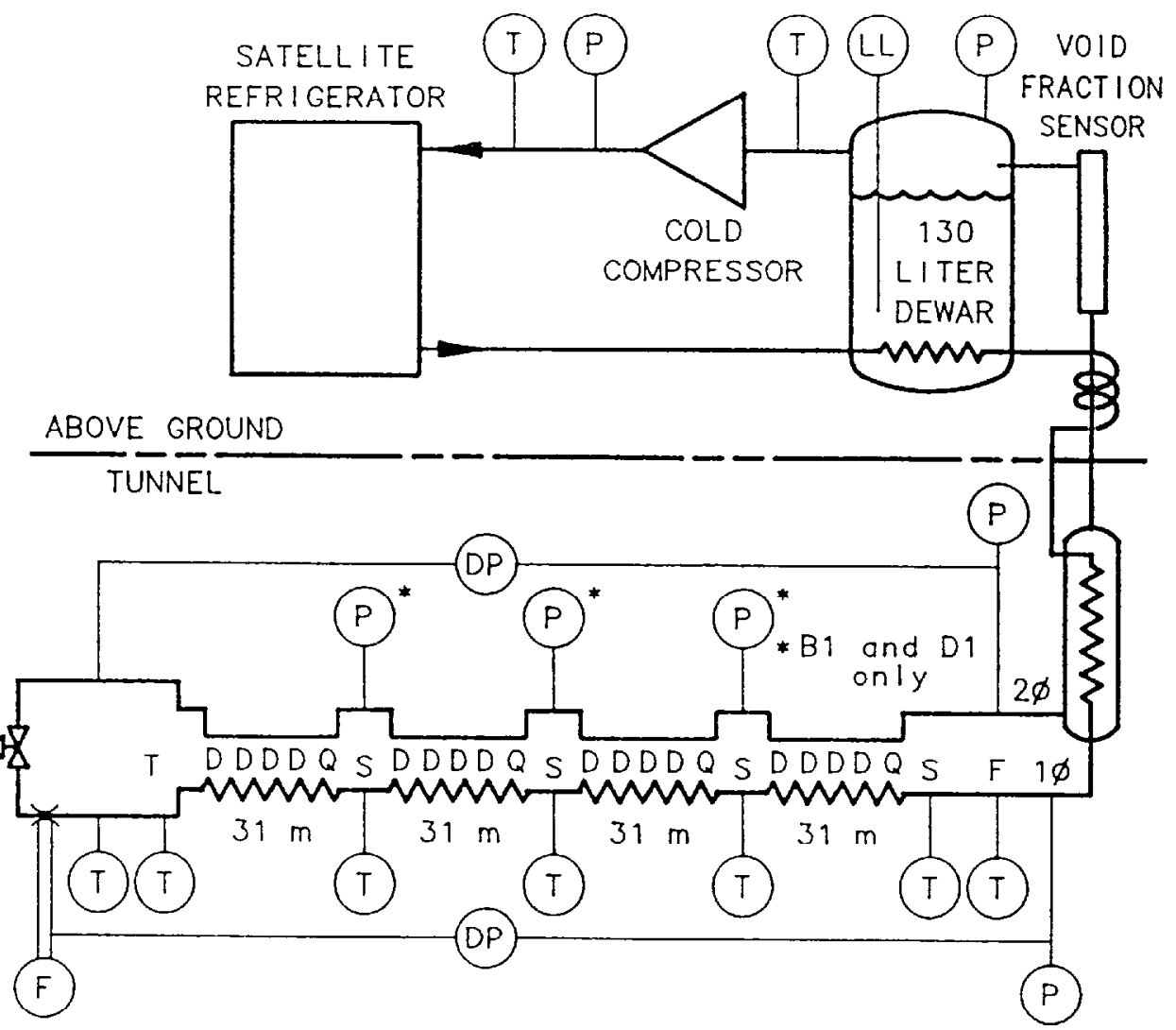

Figure 1. Schematic layout of a satellite refrigerator and one of its two $12.5 \mathrm{~m}$ long magnet strings. The temperature, pressure and flow instrumentation available for the testing is shown. 
There are four half cells in a typical magnet string. The refrigerator interfaces with the magnet strings at the feedcan $(F)$. At the end of the $125 \mathrm{~m}$ magnet string, the 10 trow is throttled into $2 \emptyset$ in the turnaround hox (T).

\section{TEMPERATURE REDUCTION PROFILES}

Cold compressors regulate the temperature in a subcooling dewar located in each refrigerator. The temperature along the two $125 \mathrm{~m}$ long magnet strings is then somewhat above this temperature due to $2 \emptyset$ pressure drop and imperfect heat exchange. Temperature measurements are made in the $1 \varnothing$ approximately every $31 \mathrm{~m}$ using carbon resistor thermometers. Calibration of the themometers were made over twelve years ago, and then only down to a temperature of $4.2 \mathrm{~K}$.

Some attempts have been made to recalibrate the thermometers in place by depressurizing the $1 \varnothing$, allowing it to go two-phase, while measuring the pressure. This becomes a very tedious task, requiring considerable downtime and large swings in helium inventory. The calibration results have been mixed, depending on the piping geometry in the components which house the thermometer.

Experience has shown that long-term changes in the thermometer calibration do not effect the slope of the response. As a result, temperature changes measured by the same thermometer remain accurate even though absolute measurement is off. We used this fact to our advantage by considering temperature reductions from a known baseline instead of absolute temperatures. This baseline is "known" only through magnet quench performance and not absolute temperature. Since the ultimate goal of the project is to increase the quench energy of the Tevatron, this is an acceptable characterization for a baseline. The baseline for the Tevatron is a quench energy of $935 \mathrm{GeV}$ at a dewar temperature of $4.50 \mathrm{~K}$.

In order to estimate the increase in quench energy of the Tevatron for a given reduction in dewar operating temperature, we need to know how effectively we reduced the temperature throughout the magnet strings. Figure 2 shows a temperature reduction plot for the $\mathrm{C} 3$ satellite magnet system. The cold compressor was used to reduce the temperature of the subcooling dewar from the nominal $4.45 \mathrm{~K}$ to $3.68 \mathrm{~K}$. This $770 \mathrm{mK}$ reduction is shown in the center of the figure at location "CC" (cold compressor). Left and right of this point

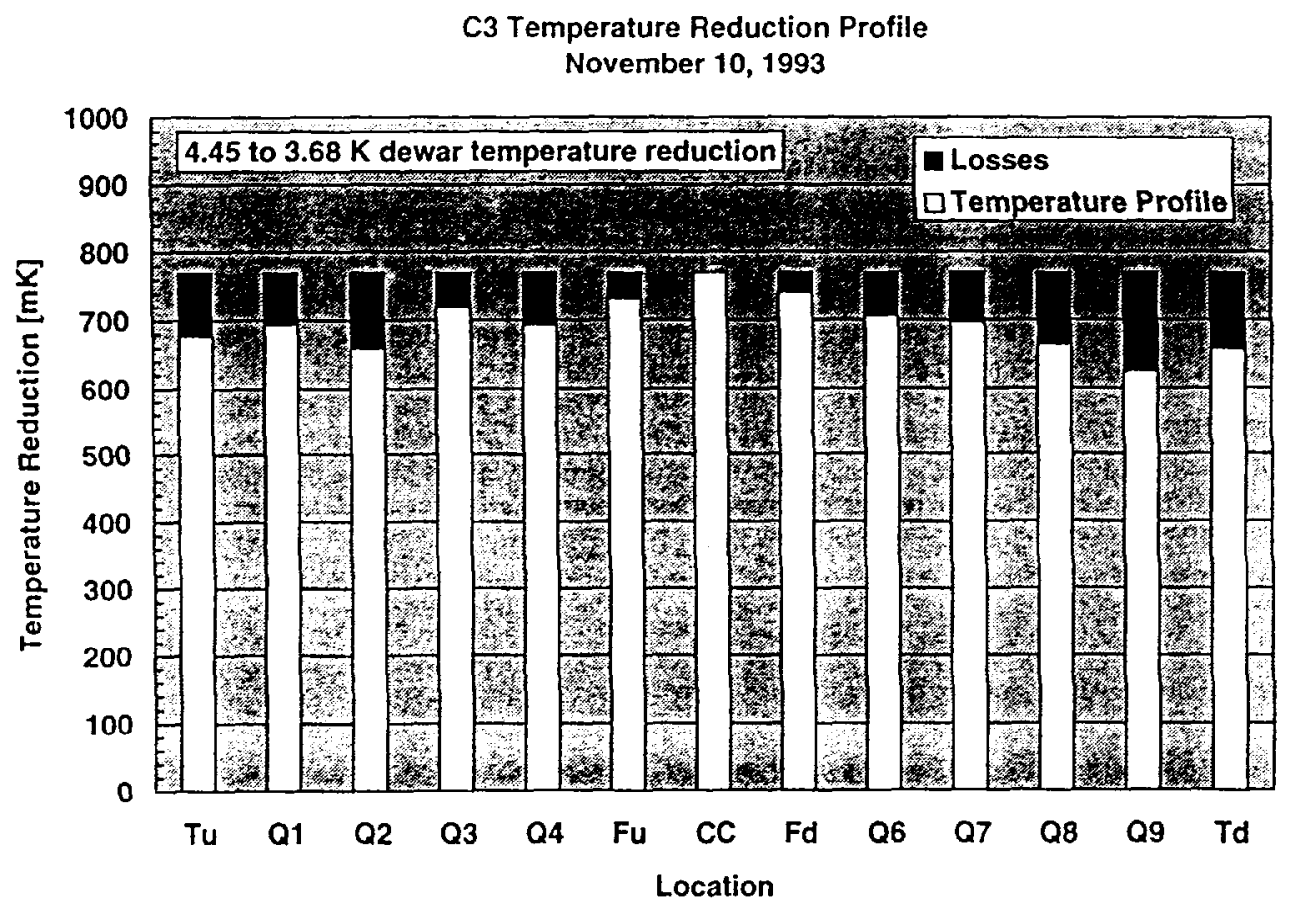

Figure 2. Tempernture reduction profile for the $\mathrm{C} 3$ magnet system. 


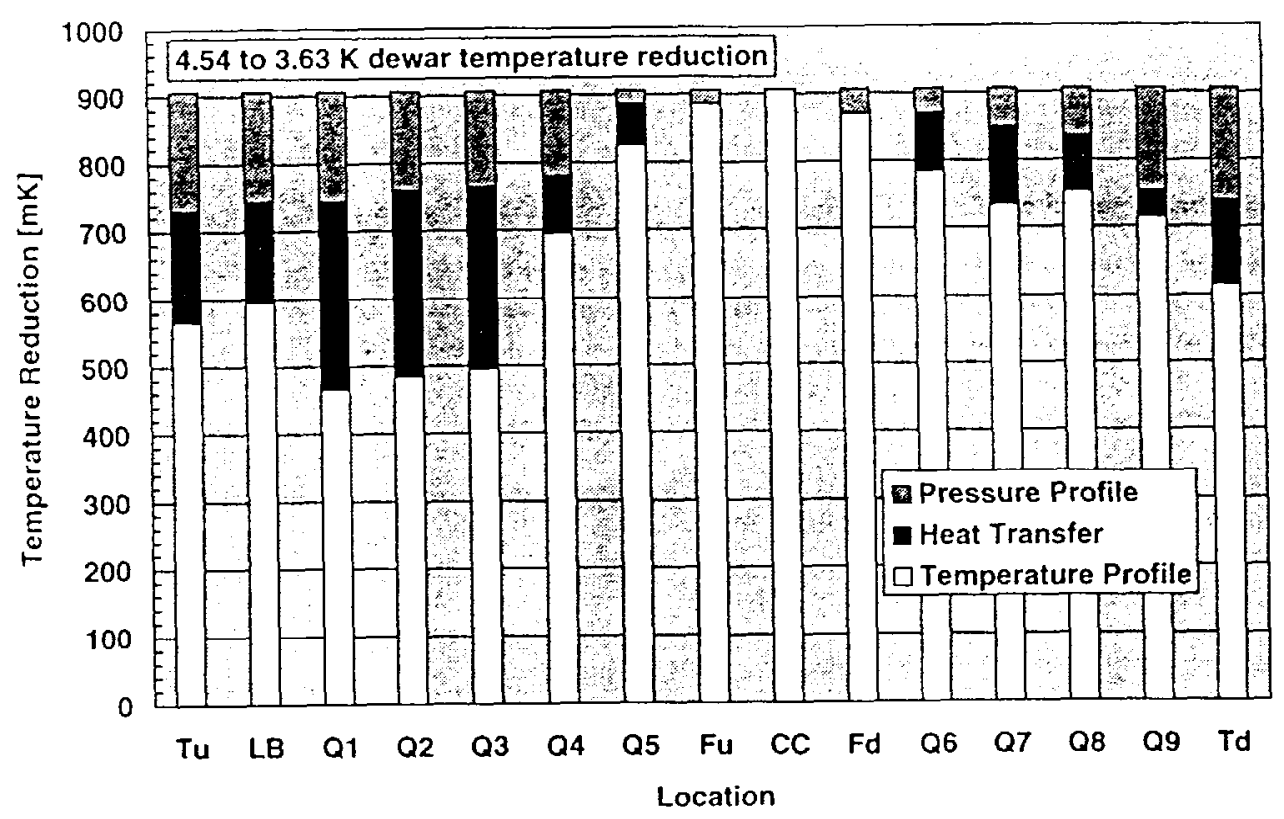

Figure 3. Temperature reduction profile for the B l magnet system including special quadrupxle magnets.

represents the $125 \mathrm{~m}$ long upstream and downstream magnet strings, respectively.

Columns labeled with a " $F$ " and " $T$ " represent the feedcan and tumaround boxes, as in Figure 1. Columns labeled Q\# represent the thermometer in the spool piece, located every half cell (approximately every $31 \mathrm{~m}$ ). The lighter colored column represents the actual temperature reduction realized at each location. The dark section represents pressure drop and heat transfer losses from the maximum temperature reduction, in this case $770 \mathrm{mK}$.

Figure 2 shows that over $80 \%$ of the temperature reduction was realized at all locations throughout the two magnet strings. This is consistent with predictions for $2 \varnothing$ pressure drop and the change in helium specific heat. This is not the case, however, in Figure 3 for the Bl satellite magnet system. In this case, only $50 \%$ of the temperature reduction was realized over much of the upstream string. The only significant difference between $\mathrm{C} 3$ and $\mathrm{B} 1$ is that $\mathrm{B} 1$ has additional quadrupole magnets installed. The most significant of these quadrupole magnets are located at Q3, Q2, Q1, and LB, corresponding to the highest loss in temperature reduction.

In order to better understand the losses, additional pressure transducers were added to the $2 \varnothing$ circuit. This allowed us to separate the losses into pressure drop and heat transfer components. Included in the heat transfer component is the effect of reduced helium heat capacity. From Figure 3, it is shown that a local pressure drop hetween Q8 and Q9 accounts for the discrepancy on the downstream string. Over the history of the Tevatron, several obstructions (rags) have been removed from the cryogenic circuits of the magnet system. Recently, one was removed from between Q2 and Q3 at B1. During that time, all 2q interfaces in B 1 were inspected and no further obstructions were found. It is suspected that an obstruction may be deep inside a component, probably a spool piece, and not visible from the interface.

A $2 \varnothing$ pressure drop is also shown on the upstream string between Q4 and Q5. Although this loss is quite significant, representing $11 \%$ of the temperature reduction, there is even larger heat transfer loss term. This loss is not currently understood, but has also been observed in another satellite magnet system which also has additional quadrupole magnets installed. Further temperature reduction profile testing in other satellite magnet systems is required in order to understand if this large loss is only associated with the additional quadrupole magnets. 


\section{MAGNET SYSTEM TIME RESPONSE}

The time response of the $2 \phi$ circuit was measured and calculated when the Tevation was commissioned to be about 6 minutes. The time response has to do with adding or removing helium inventory caused by a change in flow rate or heat load ( $\triangle \mathrm{C}$ losses due $i$ ) cyclical ramping of the accelerator). It was desirable to investigate whether the time response changes significantly at lower temperature in order to develop an appropriate controlling scheme.

Figure 4 shows the lime response of the 24 pressure and 1 s temperature at the end of is magnet string following a $170 \mathrm{mK}$ reduction in the cold compressor regulation point. The dark solid line represents the dewar temperature, as measured by the vapor pressure. It took approximately 2.5 minutes for the cold compressor to pump down the dewar to the new set point. The figure also shows that the regulation is quite stable.

The line labeled $\mathrm{dP}$ represents the temperature difference due to pressure drop along the $2 \varnothing$ circuit of the magnet string. The time response of the $2 \varnothing$ pressure drop is about 6 minutes, consistent with previous measurements at $4.5 \mathrm{~K}$.

The line labeled dT represents the temperature difference between the 1 a at the end of the magnet string and the $2 \not$ at the end of the string. The time response is considerably longer at 21 minutes. This time is curiously similar to the travel time of helium through the $1 \varnothing$ of a magnet string. It is believed that this is only a coincidence. The relatively high heat leak and continuous heat exchange design of the magnets make it unlikely that the helium travel time would effect this.

The sum of the $\mathrm{dP}$ and $\mathrm{dT}$ loss is plotted in the solid gray line. The long time response of the heat transfer to the $1 \varnothing$ will require a waiting period prior to restarting the accelerator to high energy after a cool down following a quench or maintenance period.

\section{SYSTEM $\Delta \mathrm{T}$}

Tests in the previous section were performed with a constant mass flow rate and varying the $2 \varnothing$ pressure. This section addresses tests performed with a constant $2 \varnothing$ pressure and varying mass flow rate. The primary purpose of the test was to measure the $2 \varnothing$ pressure drop versus flow rate. This was being investigated as a possible explanation for differences between quench levels attained in 1991 and 1993 testing.

B2 Upstream $1 \phi$ to $2 \phi \delta T$ December 21, 1994

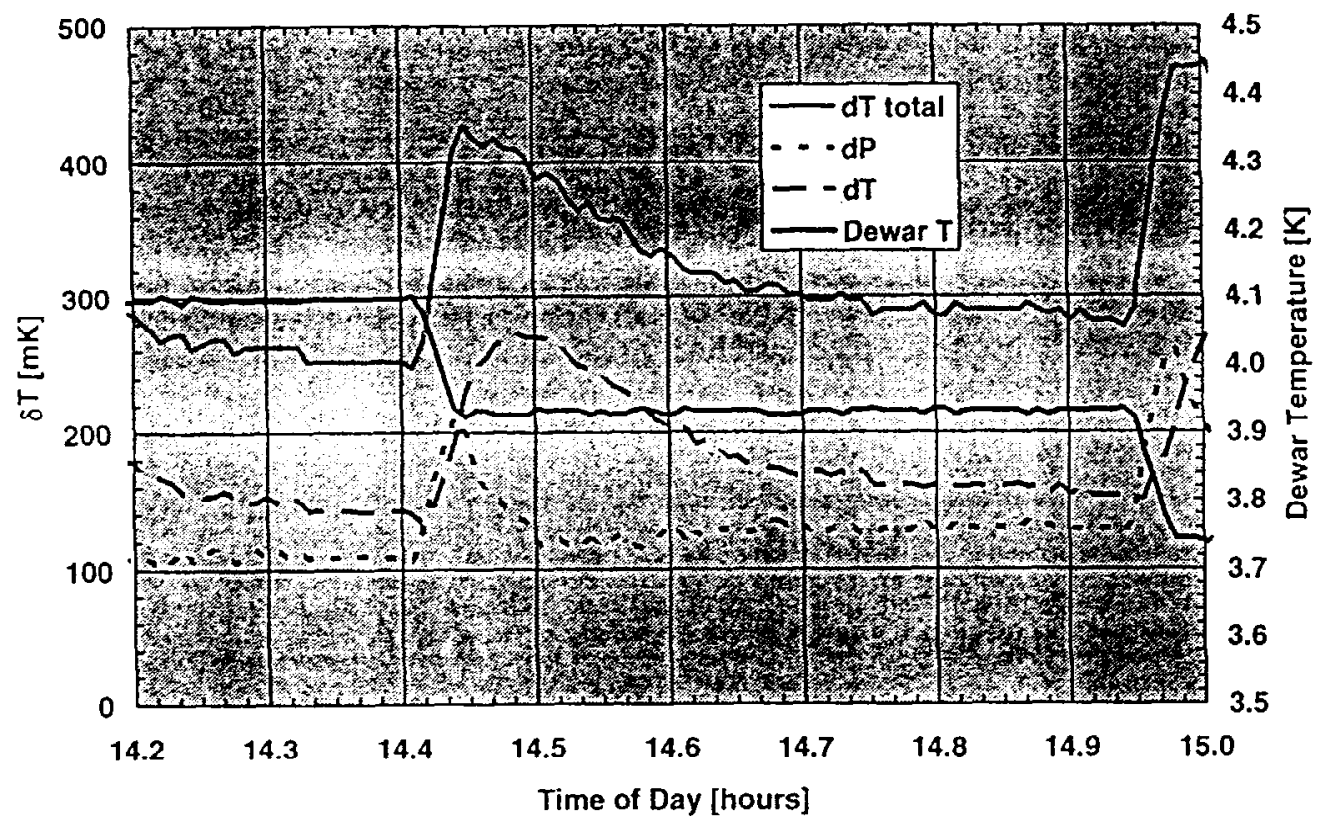

Figure 4. System Response to a step change in dewar pressure at constant mass flow rate. 
B2 Upstream $1 \phi$ to $2 \phi \delta T$

January 16,1995

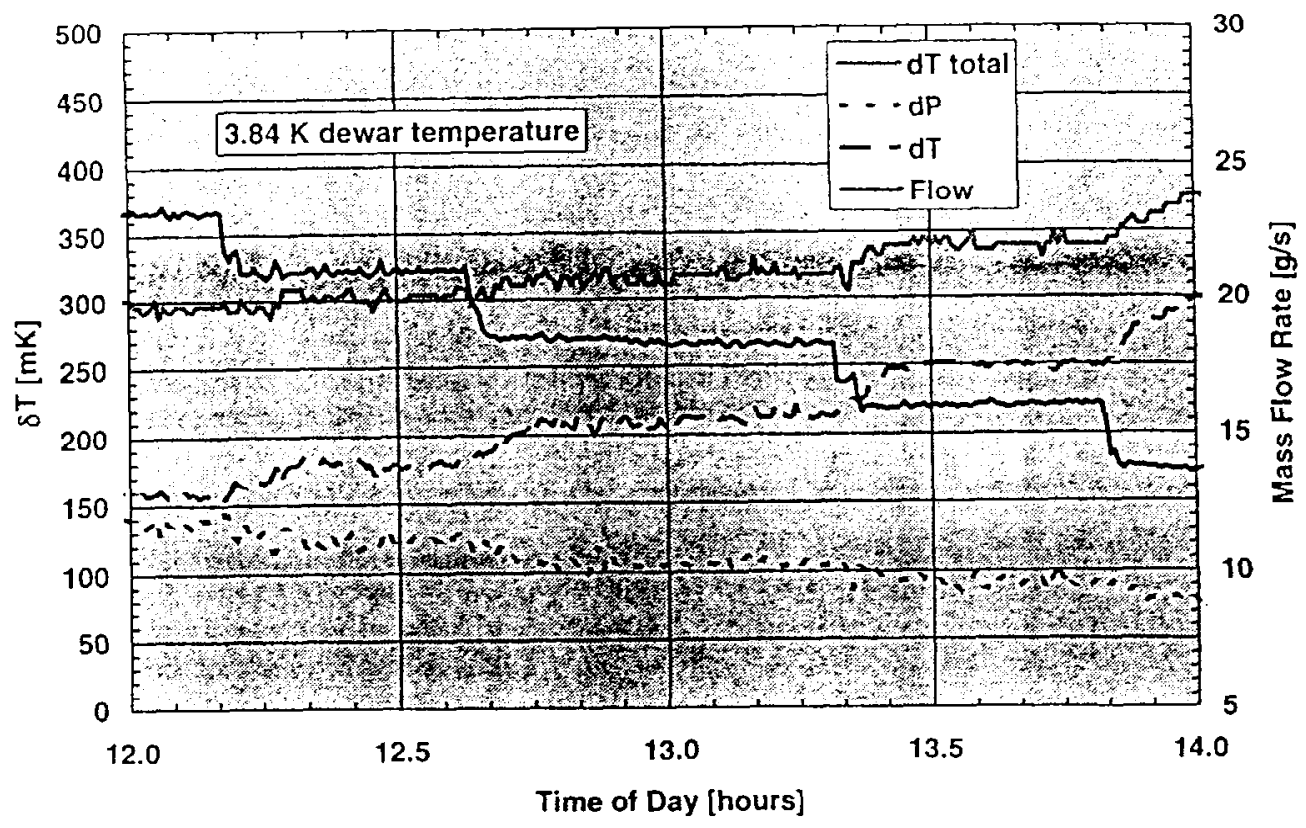

Figure 5. System response to a slep changes in mass flow ratle all comblan dewat operating pressure.

Varying the mass flow rate in the Tevatron $2 \varnothing$ changes the void fraction throughout the length of the magnet string. Vapor generation is due to heat load, which is fixed when the Tevatron is not powered. Decreasing the mass flow rate reduces the amount of liquid which travels the length of the $2 \varnothing$ circuit, but the vapor mass flow rate remains constant.

Figure 5 is a time plot of the same three differential temperature parameters from Figure 4 plotted with the magnet string mass flow rate at a constant dewar temperature of $3.84 \mathrm{~K}$. The mass flow rate was decreased by approximately $2 \mathrm{~g} / \mathrm{s}$ increments from $23 \mathrm{~g} / \mathrm{s} \mathrm{to}$ $14 \mathrm{~g} / \mathrm{s}$. Each step was allowed to stabilize for a half an hour based on the experience gained from the time response tests.

For the first three mass flow steps, the $1 \varnothing / 2 \varnothing$ mass flow rate was reduced by $26 \%$. Over the same range, the $\Delta \mathrm{T}$ corresponding to pressure drop decreased by $36 \%$. What hadn't been anticipated was that the $\Delta \mathrm{T}$ between the $1 \varnothing$ and $2 \phi$ increased by $56 \%$. This heat transfer effect dominated, resulting in a net increase in $\Delta T$ between the $1 \varnothing$ and the dewar as the mass flow rate was reduced, as shown by the dT total line in Figure 5.

The last mass flow rate reduction shown in Figure 5 resulted in a considerable increase in $1 \varnothing$ to $2 \varnothing \Delta T$. It is helieved that this mass flow rate is very close to the flow necessary to maintain the static heat leak of the magnet string. Operation in this range becomes very unstable when changes, positive or negative, are made in the system.

The results of this test suggests that higher how rates will allow for lower coil temperatures and thus higher quench energies. This result could explain the difference in quench energies observed between the 1991 and 1993 testing. Between that time, the injection point for the liquid helium flow from the CHL was moved from the lot to the subcooling dewar. This results in a net reduction of 1 (क/26 mass flow rate of about $6 \mathrm{~g} / \mathrm{s}$ per satellite, or $3 \mathrm{~g} / \mathrm{s}$ per magnet string.

\section{CONCLUSIONS AND RECOMMENDATIONS}

Further testing is required in order to understand the operation and control of the Tevatron lower temperature upgrade. Enhancements to the controls are necessary for both operations and further testing. Automatic cool down schemes need to be refined to consider the results of mass flow rate and time response effects. 
Enhancements also need to be made to automate further testing in other satellite magnet systems. Automatic control schemes need to be developed for carbon resistor calibration and temperature reduction profiles. This is the only way to ensure uniformity in technique while eventually testing twenty-four satellite magnet systems.

Additional tests are planned to understand the heat transfer in a Tevatron half cell. A stand-alone half cell string test is planned with highly instrumented magnets. The goals of the test are to understand the heat leak to the $1 \phi$ and $2 \phi$ circuits, the $1 \phi$ to $2 \phi$ heat transfor. the $1 \varnothing$ inner and outer flow split, $1 \varnothing$ and $2 \phi$ stratification, and $A C$ losses.

\section{ACKNOWLEDGMENT}

The author acknowledges the dedication shown by the Accelerator Division Cryogenics Department in supporting the operation the Tevatron cryogenic system and the tests presented in this paper. The data logging and plotting tools supplied by the Accelerator Division Controls Department were invaluable to this work.

\section{REFERENCES}

1. J. C. Theilacker, Upgrade of the Tevatron cryogenic system, in: "Advances in Cryogenic Engineering, " Vol. 39, Plenum Press, New York (1994), p. 517.

2. B. L. Norris et al, New cryogenic controls for the Tevatron low temperature upgrade, in: "Advances in Cryogenic Engineering, "Vol. 39, Plenum Press, New York (1994), p. 1185.

3. J. C. Theilacker, Tevatron cold compressor operating experience, in. "Cryogenics," Vol. 34, ICEC. Supplement, Butterworth-1Heinemann, Oxtord (1994), p. 107. 